\title{
Platelet-Activating Factor-Induced Ischemic Bowel Necrosis: The Effect of Platelet-Activating Factor Acetylhydrolase
}

\author{
MASAYUKI FURUKAWA, EDWARD L. LEE, AND JOHN M. JOHNSTON \\ Departments of Biochemistry [M.F., J.M.J.], Obstetrics-Gynecology [M.F., J.M.J.]. Pathology [E.L.L.], and \\ The Cecil H. and Ida Green Center for Reproductive Biology' Sciences [M.F., J.M.J.J. \\ The University of Texas Southwestern Medical Center at Dallas, Dallas, Texas 75235-9051 and \\ Veteran's Affairs Medical Center [E.L.L.], Dallas, Texas 75216
}

\begin{abstract}
In the present investigation, the rat model of necrotizing enterocolitis (NEC) was further developed by injection of platelet-activating factor (PAF) in the descending aorta. The role of the plasma PAF-acetylhydrolase (PAF-AH) was examined in the prevention of this disease. PAF $(0.35 \mu \mathrm{g})$ caused ischemic intestinal necrosis when administered intraaortically. The effects of PAF injection on the small intestine were examined histologically in samples of the duodenum, jejunum, and ileum. The administration of PAF resulted in extensive hemorrhagic damage in all regions of the small bowel and a marked hemoconcentration. Pretreatment of the rats with dexamethasone or medroxyprogesterone significantly increased plasma PAF-AH activity. Dexamethasone and medroxyprogesterone prevented the gross and histologic features of NEC as well as the hemoconcentration. In contrast, lower amounts of PAF were sufficient to cause bowel necrosis and hemoconcentration when decreased activities of plasma PAFAH were induced by $17 \alpha$-ethynylestradiol or 4-aminopyrazolopyrimidine administration. We have recently reported that PAF-AH is present in human milk. The beneficial effect of breast feeding in preventing the development of NEC in the newborn is discussed and a mechanism proposed to explain this finding. It is suggested that PAF may play an important role in the pathogenesis of NEC and that the increased plasma activity of PAF-AH caused by dexamethasone and the presence of this enzyme, of milk origin, in the lumen of the small bowel may prove to be beneficial in the prevention of this disease. (Pediatr Res 34: 237-241, 1993)
\end{abstract}

\section{Abbreviations}

NEC, necrotizing enterocolitis

PAF, platelet-activating factor

PAF-AH, PAF-acetylhydrolase

4-APP, 4-aminopyrazolopyrimidine

BSA, bovine serum albumin

PAF (1-O-alkyl-2-acetyl-sn-glycero-3-phosphocholine) is a naturally occurring lipid mediator that has a variety of biologic functions and is active in the nanomolar range (1). Recently, it was reported that PAF was one of the most potent ulcerogens of

Received for rapid publication April 21, 1993.; accepted May 17, 1993.

Correspondence: Dr. John M. Johnston, Department of Biochemistry, UT Southwestern Medical Center, 5323 Harry Hines Blvd., Dallas, TX 75235-90521.

Supported in part by NIH Grants HD13912 and HD11149, The Chilton Foundation, and The Robert A. Welch Foundation, Houston, TX. the gastrointestinal tract yet described (2), inducing acute mucosal injury in the stomach and small intestine $(2,3)$. GonzalezCrussi and Hsueh (4) have previously reported a model of NEC produced in the rat by injecting PAF and lipopolysaccharide into the descending aorta. These investigators have also reported that the PAF concentration in plasma was elevated and that the activity of PAF-AH was significantly lower in patients with NEC (5).

The importance of PAF-AH in the regulation of the PAF concentration in a number of conditions has recently been emphasized (6). The plasma activity of this enzyme has been shown to increase during the "stress" reaction of the lizard (7), in patients with ischemic cerebrovascular disease (8), with insulin-dependent diabetes mellitus (9), in spontaneous hypertensive rats (10), and in Caucasian males with hypertension (1). The plasma activity is decreased in asthmatic children (11) and in the maternal plasma during the latter stages of pregnancy (12). Furthermore, it has been shown that the activity of the plasma isozyme of PAF-AH is regulated by various steroid hormones in vivo $(13,14)$ and in different cell types $(6,15)$. Recently, we have reported that PAF-AH is present in human milk (16). The enzyme is the isozyme of the plasma type and is resistant to exposure to low $\mathrm{pH}$ and proteolysis. This observation suggests that the PAF-AH of human milk may be important in the prevention of PAF accumulation in the small intestinal mucosa. In the present investigation, we have further developed a rat model of NEC by injection of PAF and examined the role of PAF-AH on this disease.

\section{MATERIALS AND METHODS}

Chemicals. [ $\left.{ }^{3} \mathrm{H}\right]$ PAF (1-hexadecyl-2- $\left[{ }^{3} \mathrm{H}\right]$ acetyl-sn-glycero-3phosphocholine; specific radioactivity $=10 \mathrm{mCi} / \mu \mathrm{mol}$ ) was purchased from DuPont-New England Nuclear (Boston, MA). Unlabeled PAF was obtained from Avanti Polar Lipids (Pelham, AL) and purified before use by thin-layer chromatography on silica gel (Merck, Darmstadt, Germany), using chloroform:methanol:acetic acid:water $(50: 30: 8: 6)$ as mobile phase. BSA (essentially fatty acid free), dexamethasone, $17 \alpha$-ethynylestradiol, DMSO, and 4-APP were purchased from Sigma Chemical Co. (St. Louis, MO). Medroxyprogesterone was obtained from Steraloid, Inc. (Wilton, NH). Wistar rats were obtained from Simonsen Laboratories, Inc. (Gilroy, CA).

Hormonal treatment. Hormones were first dissolved in ethanol, followed by dilution with DMSO. The final concentration of ethanol was $20 \%$. Rats were injected s.c. with vehicle or hormones for $3 \mathrm{~d}$, from $\mathrm{d} 1$ to $\mathrm{d} 3$, as previously described. The daily doses administered were $0.5 \mathrm{mg} / \mathrm{kg}$ for dexamethasone, 50 $\mathrm{mg} / \mathrm{kg}$ for medroxyprogesterone acetate, and $0.25 \mathrm{mg} / \mathrm{kg}$ for $17 \alpha$-ethynylestradiol. Blood samples were collected from the tail 
vein into heparinized capillary tubes on $\mathrm{d} 1$ (before the hormone injection). The plasma was isolated by centrifugation at $600 \times g$ for $5 \mathrm{~min}$, hematocrit was measured, and the plasma stored at $-20^{\circ} \mathrm{C}$ before assay. The 4th sample was obtained $24 \mathrm{~h}$ after the final injection. In some cases, samples were also obtained on d 7 and 14.

4-APP treatment. 4-APP was administered intraperitoneally for $3 \mathrm{~d}$ at a dose of $2 \mathrm{mg} / 100 \mathrm{~g}$ body weight. The 4-APP was dissolved in normal saline and prepared fresh just before use. Food, but not water, was withheld from the 4-APP- and vehicletreated animals.

Assays. The activity of plasma PAF-AH was assayed according to the method of Miwa et al. (11) with minor modifications. $\left[{ }^{3} \mathrm{H}\right]$ acetyl-PAF and nonradiolabeled PAF were suspended in BSA (0.1\%). A $0.05 \mathrm{mM}$ final concentration of PAF $(40 \mu \mathrm{Ci} / \mu \mathrm{mol})$ was used in the assay tube. Rat plasma was diluted 20 -fold with $0.25 \mathrm{M}$ sucrose before assay. The assay mixture contained 0.3 $\mathrm{mL}$ of Tris- $\mathrm{HCl}(50 \mathrm{mM}, \mathrm{pH} 7.4)$ containing BSA $(2.0 \mathrm{~g} / \mathrm{L})$, various amounts of diluted plasma, and radiolabeled PAF substrate. The final volume was $0.5 \mathrm{~mL}$. A standard serum sample from a human source was assayed with each assay group. No significant change was found in the standard throughout the study. The assay mixture was incubated for $20 \mathrm{~min}$ at $37^{\circ} \mathrm{C}$. The reaction was terminated by addition of $0.5 \mathrm{~mL}$ of trichloroacetic acid $(14 \%)$, and the mixture centrifuged for $5 \mathrm{~min}$ at $4^{\circ} \mathrm{C}(600 \times$ $g$ ). One tenth of a milliliter of the supernatant was removed and mixed with $5 \mathrm{~mL}$ of scintillation fluid (Budget Solve; Research Products International Corp.. Mount Prospect, IL).

Surgical preparation. The model used to produce the NEClike disease is similar to that previously described by GonzalezCrussi and Hsueh (4). Either male or female Wistar rats, $200 \pm$ $20 \mathrm{~g}$, were used in all experiments. The rats were anesthetized with pentobarbital sodium $(40 \mathrm{mg} / \mathrm{kg})$, the abdomen was incised along the midline, and various amounts of PAF, dissolved in $0.25 \%$ BSA in $0.9 \%$ saline, were injected into the abdominal aorta at the level of the renal arteries. The final injection volume was $0.2 \mathrm{~mL}$. After injection, the abdomen was closed, and the animals were killed within $2 \mathrm{~h}$ after injection. When up to $2 \mu \mathrm{g}$ of PAF was injected through the tail vein, no necrosis was observed. The entire small intestine was removed, the intestinal contents were gently washed out with cold saline, and sections (upper, middle, and lower) of tissue were fixed in alcoholic formalin. The tissues were stained with hematoxylin and eosin. Blood samples were collected before and after injection for determination of PAF-AH activity and hematocrit.

\section{RESULTS}

Gross and microscopic description. The entire small bowel of the rats was removed from the ligament of Treitz to the cecum. The serosa and mucosa were unremarkable (Fig. $1 A$, panel 1 ). In the PAF-treated rats, the serosal surface was diffusely discolored and hemorrhagic (Fig. 1A, panel 2). On opening the bowel. lumen and mucosa were also diffusely hemorrhagic and necrotic. Microscopically, the vehicle-treated rats demonstrated normal villous architecture and a normal population of cells within the lamina propria (Fig. $1 B$, panel 1 ). The PAF-treated rats demonstrated diffuse full-thickness necrosis and hemorrhage of the mucosa (Fig. 1B, panel 2).

Dose-dependent administration of PAF. The results of our observations are summarized in Table 1; various amounts of PAF were administered for different time periods. As shown in Table 1, PAF at a dose of $0.35 \mu \mathrm{g}$ was sufficient to cause bowel necrosis, whereas PAF at doses of $0.25 \mu \mathrm{g}$ or lower was ineffective in causing bowel necrosis as judged by gross examination. These observations were confirmed by histologic examination. The histologic examination of sections of the duodenum. jejunum. and ileum revealed tissue pathology that was identical to that seen in patients with NEC. A significant number of animals developed the disease within $\mathrm{I} h$ if a high concentration of PAF was injected (greater than $1 \mu \mathrm{g}$ ). When $2 \mu \mathrm{g}$ of PAF was administered via the tail vein. no bowel necrosis was observed at the end of a 2-h period. When as little as $0.35 \mu \mathrm{g}$ of PAF was administered into the mesenteric artery, the gross and microscopic finding of the necrosis could be detected within $15 \mathrm{~min}$.

Effect of dexamethasone on plasma PAF-AH activity and NEC development. Previously, we have reported that dexamethasone injection increased the plasma PAF-AH activity in adult male and female rats $(13,14)$. When dexamethasone was administered, the activity returned to normal levels within $7 \mathrm{~d}$. In the reported experiments (Table 2), the plasma activity in rats treated with dexamethasone increased from $55.2 \pm 7.1 \mathrm{nmol} \times \mathrm{min}^{-1} \times \mathrm{mL}^{-1}$ plasma on $d 1$ to $117.5 \pm 7.9 \mathrm{nmol} \times \mathrm{min}^{-1} \times \mathrm{mL}^{-1}$ plasma by d 4. When $0.35 \mu \mathrm{g}$ of PAF was injected into the abdominal aorta of dexamethasone-treated rats on $\mathrm{d} 4$, the gross and microscopic finding illustrated in Figure $1 A$ and $B$, panel 3, was observed. As can be seen, the serosa and mucosa of the small intestine were normal upon both gross and microscopic examination. As was previously shown, this concentration of PAF causes a marked necrosis in untreated rats. It thus appears that the administration of dexamethasone completely protected the animals from the necrosis.

Effect of medroxyprogesterone, estrogen, and 4-APP on plasma $P A F-A H$ activity: Results similar to those obtained with dexamethasone were observed when PAF was administered to the medroxyprogesterone-treated rats on $\mathrm{d} 4$, as judged by both the gross and histologic findings. The PAF-AH activity of the medroxyprogesterone-treated animals increased from $52.0 \pm 4.9$ $\mathrm{nmol} \times \mathrm{min}^{-1} \times \mathrm{mL}^{-1}$ on $\mathrm{d} 1$ to $83.5 \pm 2.7$ on $\mathrm{d} 4$. In contrast to the dexamethasone-treated animals, the PAF-AH activity of the medroxyprogesterone-treated group remains elevated for up to $21 \mathrm{~d}$ (14). The PAF-AH activity of medroxyprogesterone treated group was $80.4 \pm 0.6 \mathrm{nmol} \times \mathrm{min}^{-1} \times \mathrm{mL}^{-1}$ on $\mathrm{d} 14$. No necrosis was observed when PAF was administered to these animals on $\mathrm{d} 14$. When $17 \alpha$-ethynylestradiol was injected, the plasma PAF-AH activity decreased from $50.7 \pm 9.9 \mathrm{nmol} \times$ $\mathrm{min}^{-1} \times \mathrm{mL}^{-1}$ on $\mathrm{d} 1$ to $3.3 \pm 1.1$ by $\mathrm{d} 4$. When these animals received injections of PAF on $d 4$, it was found that as little as $0.25 \mu \mathrm{g}$ of PAF was sufficient to cause bowel necrosis and hemoconcentration.

4-APP has been used to lower the plasma lipoprotein concentration of the rat (17). The plasma PAF-AH activity in the rat and other species is associated with the lipoproteins (6). We had previously demonstrated that the administration of 4-APP to adult rats causes a decrease in the plasma PAF-AH (Yasuda $\mathrm{K}$. Johnston JM, unpublished observations). We therefore used 4APP to lower the plasma PAF-AH and determine its effect on the development of NEC. The PAF-AH activity of the 4-APPtreated animals was decreased from $50.9 \pm 3.3 \mathrm{nmol} \times$ min $^{-1} \times$ $\mathrm{mL}^{-1}$ on $\mathrm{d} 1$ to $5.4 \pm 3.9$ on $\mathrm{d} 4$. It was found that as little as $0.175 \mu \mathrm{g}$ of PAF was sufficient to cause bowel necrosis and hemoconcentration in these animals. The effects of the various treatments on the plasma PAF-AH at the end of $2 \mathrm{~h}$ are summarized in Table 2. The administration of PAF caused a profound hemoconcentration due to increased vascular permeability (18).

\section{DISCUSSION}

In the present investigation, we have further established the role of PAF in NEC. In this study, PAF was the sole autocoid administered. The observation that manipulation of the activity of the enzyme responsible for PAF inactivation affected the severity of the intestinal necrosis and hemoconcentration provides further evidence for the involvement of this potent autocoid. Wallace and Whittle (18) reported that there was a highly significant correlation between gastric damage score and degree of hemoconcentration due to plasma exudation in PAF-induced gastric mucosal necrosis. We have demonstrated a similar relationship in the NEC model in that treatment with either dexa- 


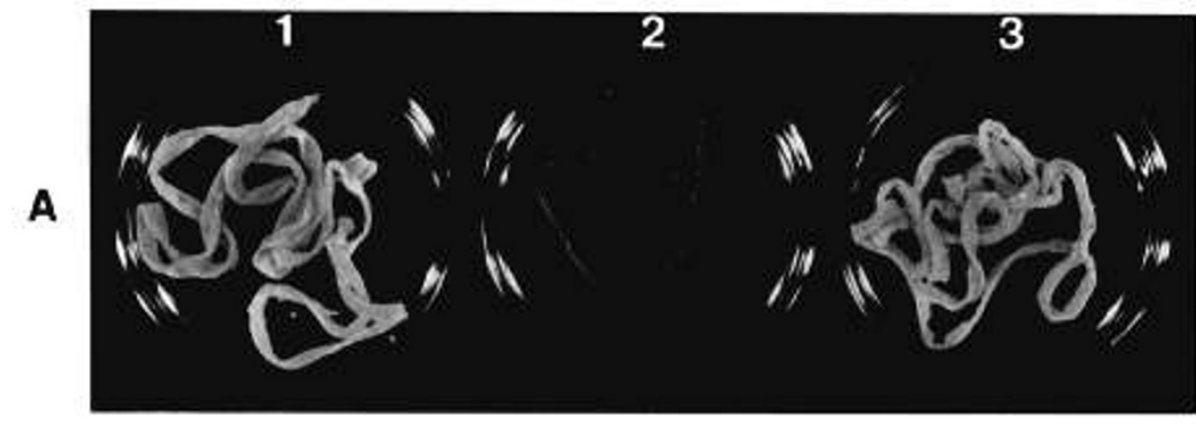

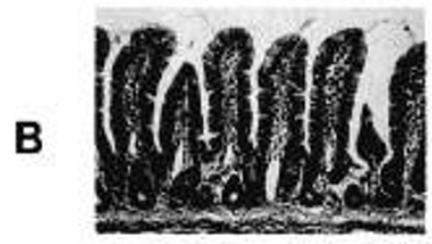

Untreated

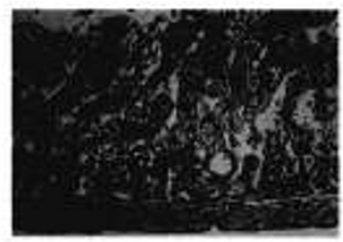

PAF

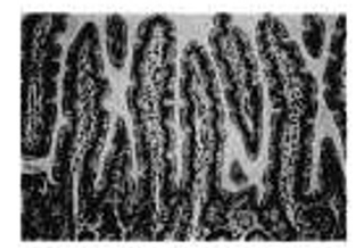

Dexamethasone pretreated

Fig. 1. The gross $(A)$ and microscopic $(B)$ sections of the rat small intestine after various treatments. 1 . Vehicle injection: 2. PAF $(0.35 \mu \mathrm{g})$ injection in the descending aorta: and $3, \operatorname{PAF}(0.35 \mu \mathrm{g})$ injection into the descending aorta of a rat that had been pretreated with dexamethasone for $3 \mathrm{~d}$.

Table 1. Experimental bowel necrosis in rats after intraaortic PAF injection*

\begin{tabular}{cccc}
\hline & \multicolumn{2}{c}{$\begin{array}{c}\text { Number of } \\
\text { animals } \\
\text { (time after PAF } \\
\text { injection) }\end{array}$} & $\begin{array}{c}\text { Number of } \\
\text { animals with } \\
(\mu \mathrm{g})\end{array}$ \\
\cline { 2 - 3 } 2 & $0-1 \mathrm{~h}$ & $1-2 \mathrm{~h}$ & necrosis \\
\hline 2 & 3 & ND & 3 \\
0.5 & 3 & ND & 3 \\
0.4 & ND & 3 & 3 \\
0.35 & ND & 2 & 2 \\
0.25 & (2) $\dagger$ & 15 & 15 \\
0.175 & ND & 5 & 0 \\
0 & ND & 2 & 0 \\
\hline
\end{tabular}

* ND, not determined.

+ Two rats killed within $1 \mathrm{~h}$ failed to manifest necrosis.

methasone or medroxyprogesterone prevented both the hemoconcentration and the intestinal damage induced by PAF. Furthermore, the requirement of a decreased PAF amount to cause NEC in animals with an extremely low PAF-AH activity further supports the hypothesis of the importance of PAF in the development of this disease.
Our observation that administration of $2 \mu \mathrm{g}$ of PAF into the tail vein failed to cause bowel necrosis but the injection of 0.35 $\mu \mathrm{g}$ of PAF into the descending aorta resulted in NEC is also supportive of a role of plasma PAF-AH in the prevention of the disease. This is because the PAF administered via descending aorta would immediately expose the small bowel to PAF, whereas that injected into the tail vein might be hydrolyzed by the plasma PAF-AH before it reaches the small bowel.

Based on the kinetic constants of the plasma enzyme, it has been calculated by Prescott et al. (6) that PAF is rapidly converted into the biologically inactive lysoPAF. In the present study, we have suggested that the modification of the activity of PAF-AH may play an important role in regulating the amount of PAF present in the circulation.

Beneficial effects of glucocorticoids and lipoxygenase inhibitors against damaging effects of PAF on the gastrointestinal tract have been reported in other animal models $(18,19)$. Wallace and MacNaughton (20) reported that the damage in the small intestine induced by PAF infusion was accompanied by an increase in the tissue formation of leukotriene $B_{4}$ in the duodenum, jejunum, and ileum. In that study, dexamethasone pretreatment for $36 \mathrm{~h}$ reduced PAF-induced intestinal damage and leukotriene $\mathrm{B}_{4}$ formation, whereas gastric damage scores were not affected. It is well established that the formation of PAF and eicosanoids are closely related (1). The effect of glucocorticoids on decreasing

Table 2. Effect of various agents on plasma PAF-AH activity. PAF-induced experimental how'el necrosis, and hematocrit*

\begin{tabular}{|c|c|c|c|c|}
\hline Pretreatment & $\begin{array}{l}\text { Number } \\
\text { of animals }\end{array}$ & $\begin{array}{c}\text { Number } \\
\text { of animals } \\
\text { with necrosis }\end{array}$ & $\begin{array}{c}\text { PAF-AH activity } \\
\left(\mathrm{nmol} \times \mathrm{min}^{-1} \times \mathrm{mL}^{-1}\right)\end{array}$ & $\begin{array}{l}\% \text { Change in } \\
\text { hematocrit }\end{array}$ \\
\hline Control & 8 & 8 & $53.8 \pm 4.7$ & $+68.9 \pm 3.8$ \\
\hline Dexamethasone & 8 & 0 & $117.5 \pm 7.9$ & $-5.0 \pm 6.0$ \\
\hline Medroxyprogesterone & 6 & 0 & $83.5 \pm 2.7$ & $-6.4 \pm 1.3$ \\
\hline Medroxyprogesterone $\dagger$ & 3 & 0 & $80.4 \pm 0.6$ & $-3.1 \pm 0.5$ \\
\hline $17 \alpha$-Ethynylestradiol & 3 & 3 & $3.3 \pm 1.1$ & $+22.5 \pm 4.0$ \\
\hline 4-APP & 3 & 3 & $5.4 \pm 3.9$ & $+39.7 \pm 2.3$ \\
\hline
\end{tabular}

- Dexamethasone- and medroxyprogesterone-treated rats received injections of $0.35 \mu \mathrm{g}$ of PAF into the descending aorta. The $17 \alpha$-ethynylestradiol- and 4-APP-treated animals received 0.25 and $0.175 \mu \mathrm{g}$ of PAF, respectively. All animals were killed $2 \mathrm{~h}$ after injection. The percent change in hematocrit represents the difference between before and after PAF injection. Most experiments were carried out on d 4.

+ Experiment carried out on $\mathrm{d} 14$. 
eicosanoid synthesis is well established. We have suggested a role for glucocorticoids in decreasing PAF via the increase in the plasma PAF-AH activity $(13,14)$. The beneficial effect of glucocorticoids in the prevention of NEC is most probably due to the effect of this hormone on the plasma activity of PAF-AH and not its direct effect on the intestine, inasmuch as medroxyprogesterone has a similar protective effect on the development of NEC and on the stimulation of the plasma PAF-AH activity. This was true for medroxyprogesterone even after $14 \mathrm{~d}$, when the PAF-AH activity was still elevated and a protective effect was observed. On the other hand, estrogen causes a decrease in the plasma PAF-AH activity and these animals are sensitive to lower concentrations of PAF. Similarly, the administration of a nonsteroidal agent, 4-APP, that is known to decrease the plasma PAF-AH activity also causes an increased sensitivity to PAF and the development of NEC.

Corticosteroids are widely used clinically in the treatment of inflammation, and they have been reported to decrease the mortality associated with endotoxin-induced shock (21). Interestingly, Halac et al. (22) recently demonstrated that prenatal corticosteroid therapy reduced the incidence of neonatal necrotizing enterocolitis. On the basis of the reported findings, it is suggested that one of the mechanisms involved in decreasing the incidence of NEC in the glucocorticoid-treated infants is the increase in the plasma PAF-AH activity of the treated group. The activity of PAF-AH in newborns, both animals and humans, is low at birth and increases rapidly postpartum $(12,23)$. The activity increases during the first week of life. This finding adds further support to the concept that PAF-AH may play an important role in the prevention of NEC and may explain why premature infants are more susceptible to NEC development.

The beneficial effect of breast feeding in preventing the development of NEC in human neonates has been reported by several groups $(24,25)$. Recently, we demonstrated that PAF-AH is present in human milk and that the enzyme is the plasma type isozyme (16). The milk enzyme is secreted by the milk macrophages and is resistant to exposure to a low $\mathrm{pH}$ and proteolysis. This evidence may also be important in the prevention of PAF accumulation in the small intestine because the enzyme would escape inactivation at the $\mathrm{pH}$ found in the stomach of the neonate and the protease activity in the intestine. PAF-AH has been found in the milk obtained from rat, pig, goat, or human at any postpartum period. A higher activity was found in the colostrum of the pig (16). Surprisingly little, if any, PAF-AH activity was found in bovine colostrum or milk obtained at any time postpartum (16). It has been reported that increased PAF is present in the stools of newborns with an inflammatory bowel disease (26). The beneficial effects of breast feeding on the prevention of NEC are diminished upon pasteurization (27), removal of the white cells (28), or substitution with cow's milk (29). These observations are consistent with the view that one of the beneficial effects of breast feeding may be the presence of PAF-AH in the human milk. Because PAF-AH is inactivated by heat treatment, decreased amounts would be produced after freezing or white cell removal due to macrophage destruction or loss. Bovine milk could not substitute milk of other species because it does not contain significant activity of PAF-AH.

The mechanism by which an increase in the plasma PAF-AH can serve a protective function in the prevention of experimental NEC caused by PAF infusion is apparent. In contrast, the explanation as to how the PAF-AH in milk may protect against the development of NEC is less clear. A possible mechanism may reside in the fact that in both animals and humans intact proteins are known to transverse the intestinal tract in newborns (30). This is especially true in preterm neonates, in which the permeability to macromolecules is significant $(31,32)$. Thus, the PAF$\mathrm{AH}$ of milk may penetrate the intestinal epithelium and act as a protective agent by inactivating the potent proinflammatory agent, PAF.

Increase in PAF in the small bowel in patients with NEC may be due, in part, to the inflammatory reaction to a bacterial infection. A Klebsiela species has been implicated in the development of this disease. This organism in combination with partial asphyxia was shown to produce NEC in newborn rats (33). This group also demonstrated that the incidence of NEC was reduced when newborn rats were fed fresh breast milk compared with synthetic formulas. The pathogenesis of NEC may require the action of several factors, including proinflammatory mediators and bacterial products. It is clear, however, that PAF may play an important role in the pathogenesis of NEC and that PAF-AH and dexamethasone may prove to be beneficial in the prevention of this disease.

Acknowledgment. The authors thank Dolly Tutton for editorial assistance in the preparation of this manuscript.

\section{REFERENCES}

1. Snyder F 1990 Platelet-activating factor and related acetylated lipids as potent biologically active cellular mediators. Am J Physiol 259:C697-C708

2. Rosam AC. Wallace JL. Whittle BJR 1986 Platelet-activating factor, an endogenous phospholipid, has potent ulcerogenic actions in the stomach. Nature 319:54-56

3. Wallace JL, Whittle BJR 1986 Profile of gastrointestinal damage induced by platelet-activating factor. Prostaglandins 32:137-14!

4. Gonzalez-Crussi F. Hsueh W 1983 Experimental model of ischemic bowel necrosis. The role of platelet-activating factor and endotoxin. Am J Pathol 112:127-135

5. Caplan MS, Hsueh W 1990 Necrotizing enterocolitis: role of platelet-activating factor. endotoxin, and tumor necrosis factor. J Pediatr 117:47-51

6. Prescott SM, Zimmerman GA. McIntyre TM 1990 Platelet-activating factor. J Biol Chem 262:4215-4222

7. Lenihan DJ. Greenberg N. Lee T-C 1985 Involvement of platelet activating factor in physiological stress in the lizard. Anolis carolinensis. Comp Biochem Physiol 81:81-86

8. Satoh K. Imaizumi T, Kawamura Y. Yoshida H. Takamatsu S. Mizuno S Shoji B. Takamatsu M 1988 Activity of platelet-activating factor (PAF) acetylhydrolase in plasma from patients with ischemic cerebrovascular disease. Prostaglandins 35:685-698

9. Hoffman B. Ruhling K. Spangenberg P. Osterman G 1989 Enhanced degradation platelet-activating factor in serum from diabetic patients. Homeostasis 19:180-184

10. Blank ML. Hall N, Cress EA. Snyder F 1983 Inactivation of 1-alkyl-2-acetylsn-2glycero-3-phosphocholine by a plasma acetyldrolase: higher activities in hypertensive rats. Biochem Biophys Res Commun 113:666-671

11. Miwa M. Miyake T. Yamanaka T. Sugatani J. Suzuki Y. Sakata S, Araki Y, Matsumoto M 1988 Characterization of serum platelet-activating facto (PAF) acetylhydrolase: correlation between deficiency of serum PAF acetylhydrolase and respiratory symptoms in asthmatic children. J Clin Invest 82:1983-1991

12. Maki N. Hoffman DR. Johnston JM 1988 Platelet-activating factor acetylhydrolase activity in maternal, fetal and newborn rabbit plasma during pregnancy and lactation. Proc Natl Acad Sci USA 85:728-732

13. Miyaura S. Maki N. Byrd W. Johnston JM 1991 The hormonal regulation of platelet-activating factor acetylhydrolase activity in plasma. Lipids 26:10151020

14. Yasuda K. Johnston JM 1992 The hormonal regulation of platelet-activating factor acetylhydrolase in rat. Endocrinology 130:708-716

15. Narahara N, Frenkel RA, Johnston JM 1993 Secretion of platelet-activating factor acetylhydrolase (PAF-AH) following phorbol ester-stimulated differentiation in HL-60 cells. Arch Biochem Biophys 301:275-281

16. Furukawa M. Narahara $H$. Johnston JM 1993 The presence of plateletactivating factor acetylhydrolase in milk. J Lipid Res (in press)

17. Brecher Pl. Young H 1978 Effect of 4-aminopyrazolopyrimidine and aminoglutethimide on cholesteryl metabolism and steroidogenesis in the rat adrenal. Endocrinology 102:1404-1413

18. Wallace JL. Whittle BJR 1986 Effect of inhibitors of arachidonic acid metabolism on Paf-induced gastric mucosal necrosis and haemoconcentration. $\mathrm{Br}$ J Pharmacol 89:415-422

19. Hsueh W Gonzalez-Crussi F. Arroyave JL 1986 Platelet-activating factorinduced ischemic bowel necrosis. An investigation of secondary mediators in its pathogenesis. Am J Pathol 122:231-239

20. Wallace JL. MacNaughton WK 1988 Gastrointestinal damage induced b platelet-activating factor: role of leukotrienes. Eur J Pharmacol 151:43-50

21. Nicholson DP 1982 Glucocorticoids in the treatment of shock and the adult respiratory distress syndrome. Clin Chest Med 3:121-132

22. Halac E, Halac J, Bégué EF, Casanas JM. Indiveri DR, Petit JF. Figueroa MJ. Olmas JM. Rodriguez LA, Obregón RJ, Martinez MV, Grinblat DA. Vilarrodona HO 1990 Prenatal and postnatal corticosteroid therapy to prevent neonatal necrotizing enterocolitis: a control trial. J Pediatr 117:132-138

23. Caplan M, Hsueh W. Kelly A. Donovan M 1990 Serum PAF acetylhydrolase increases during neonatal maturation. Prostaglandins 39:705-714 
24. Lucas A. Cole TJ 1990 Breast milk and neonatal necrotizing enterocolitis. Lancet 336:1519-1523

25. DeCurtis M. Paone C, Vetrano G, Romano G. Paludetto R, Ciccimarra F 1987 A case control study of necrotizing enterocolitis occurring over 8 years in a neonatal intensive care unit. Eur J Pediatr 146:398-400

26. de Boissieu D, Badoual J, Dupont C, Chaussade S, Denizot Y, Benveniste J 1991 Study of platelet-activating factor (PAF) in stools of newborn infants with hemorrhagic colitis. Arch Fr Pediatr 48:515-516

27. Narayanan I. Prakash K. Murthy NS, Gujral VV 1984 Randomized controlled trial of effect of raw and holder pasteurised human milk and of formula supplements on incidence of neonatal infection. Lancet 2:1111-1113

28. Pitt J, Barlow B, Heird WC 1977 Protection against experimental necrotizing enterocolitis by maternal milk. I. Role of milk leukocytes. Pediatr Res 11:906-909

29. Park DA, Bulkley GB, Granger DN 1983 Role of oxygen-derived free radicals in digestive tract disease. Surgery $94: 415-422$

30. Gardner MLG 1988 Gastrointestinal absorption of intact proteins. Ann Rev Nutr 8:329-350

31. Beach RC, Menzies IS, Clayden GS, Scopes JW 1982 Gastrointestinal permeability changes in the preterm neonate. Arch Dis Child 57:141-145

32. Roberton DM, Paganelli R, Dinwiddie R, Levinsky RJ 1982 Milk antigen absorption in the preterm and term neonate. Arch Dis Child 57:369-372

33. Barlow B, Santulli TV, Heird WC, Pitt J, Blanc WA, Schullinger JN 1974 An experimental study of acute neonatal enterocolitis: the importance of breast milk. J Pediatr Surg 9:587-595 